Highlights

\title{
Supporting contextualized learning with Linked Open Data
}

Adolfo Ruiz-Calleja, Guillermo Vega-Gorgojo, Miguel L. Bote-Lorenzo, Juan I. Asensio-Pérez, Yannis Dimitriadis, Eduardo Gómez-Sánchez

- The proposed approach generates contextualized learning tasks out of the Linked Open Data.

- This approach is applied to the domain of History of Art in the Spanish region of Castile and Leon and it semiautomatically created $16 \mathrm{~K}$ tasks using three LOD sources.

- The assessment of the tasks with 8 teachers showed that $85 \%$ of the tasks generated were aligned with the content taught in the classroom and were found to be relevant to learn in other non-formal spaces.

Preprint of article: https://doi.org/10.1016/j.websem.2021.100657 


\title{
Supporting contextualized learning with Linked Open Data
}

\author{
Adolfo Ruiz-Calleja $^{a}$, Guillermo Vega-Gorgojo ${ }^{a, *}$, Miguel L. Bote-Lorenzo ${ }^{a}$, Juan I. Asensio-Pérez ${ }^{a}$, \\ Yannis Dimitriadis ${ }^{a}$ and Eduardo Gómez-Sánchez ${ }^{a}$
}

${ }^{a}$ ETSI Telecomunicación, Universidad de Valladolid. Campus Miguel Delibes, Paseo de Belén, 15, 47011 Valladolid, Spain

\section{ARTICLE INFO}

\section{Keywords:}

automatic question generation

contextualized learning task

Linked Open Data

non-formal learning

\begin{abstract}
A B S TR ACT
This paper proposes a template-based approach to semi-automatically create contextualized learning tasks out of several sources from the Web of Data. The contextualization of learning tasks opens the possibility of bridging formal learning that happens in a classroom, and non-formal learning that happens in other physical spaces, such as squares or historical buildings. The tasks created cover different cognitive levels and are contextualized by their location and the topics covered. We applied this approach to the domain of History of Art in the Spanish region of Castile and Leon. We gathered data from DBpedia, Wikidata and the Open Data published by the regional government and we applied 32 templates to obtain $16 \mathrm{~K}$ learning tasks. An evaluation with 8 teachers shows that teachers would accept their students to carry out the tasks generated. Teachers also considered that the $85 \%$ of the tasks generated are aligned with the content taught in the classroom and were found to be relevant to learn in other non-formal spaces. The tasks created are available at https://casuallearn.gsic.uva.es/sparql
\end{abstract}

\section{Introduction}

The educational use of Linked Open Data (LOD) has been explored during the last few years. Successful cases range from recommenders of educational content to analyzers of learning processes (see [20,36]). New challenges in Technology Enhanced Learning (TEL) open new opportunities for the educational use of the LOD. One of these challenges is the connection between formal and non-formal learning, which is gaining attention in the literature (e.g., [14, 18, 34]). For example, a student who is learning History of Art at the high school (formal learning) may also learn about this same topic by visiting a historical building in her own town (non-formal learning), thus reflecting on what she learns during her classroom sessions. But how formal and non-formal learning can complement each other is a challenge because of their different nature [25]: while formal learning is a structured and intentional process that typically happens in a classroom, non-formal learning is self-directed, unplanned and many times happens incidentally.

This kind of scenarios can be supported in e-learning systems by offering students meaningful learning tasks in a wide variety of contexts where non-formal learning opportunities may arise. However, creating and adapting these contextualized learning tasks requires a significant effort that individual teachers typically cannot take on. Some applications try to overcome this issue following a social approach: a community of experts (e.g., [37]), teachers (e.g., [39]) and/or learners (e.g., [9]) create tasks that are later on offered to the students. But manually authoring structured content has shown to be problematic and difficult to scale [32,33]. In addition, this approach promotes the fragmentation of e-learning

\footnotetext{
${ }^{*}$ Corresponding author.

Email addresses: adolfo@gsic.uva.es (Adolfo Ruiz-Calleja)

guiveg@tel.uva.es (Guillermo Vega-Gorgojo)

migbot@tel.uva.es (Miguel L. Bote-Lorenzo)

juaase@tel.uva.es (Juan I. Asensio-Pérez)

yannis@tel.uva.es (Yannis Dimitriadis)

edugom@tel.uva.es (Eduardo Gómez-Sánchez)
}

systems and hinders the sharing of data among them. Other authors exploit domain-specific datasets to automatically create learning tasks [8, 22], but this strategy moves the problem to creating and maintaining these domain datasets, which still requires a significant burden.

This paper proposes an alternative approach to overcome this problem: to create a dataset of contextualized learning tasks by collecting and processing LOD. The key idea is to exploit the descriptions of entities related to the student's local area that are published on the Web of Data (WoD) to semi-automatically define learning tasks and their context, following a process driven by educational goals. This process entails integrating descriptions of entities obtained from several LOD sources, and applying a set of templates that define learning tasks and their contexts out of these descriptions. Then, all the contextualized learning tasks created are offered back as a LOD dataset, so that third-party educational applications can take advantage of them. In this paper, we present this approach and we follow it to create a LOD dataset of contextualized learning tasks to support high-school students who learn History and History of Art in the Spanish region of Castile and Leon. The educational usefulness of the generated LOD dataset is evaluated in a study that involved 8 high-school teachers. The evaluation results let us elaborate on the feasibility of the approach followed.

The rest of the paper is structured as follows. Section 2 reviews the state of the art on the creation of contextualized learning tasks. Next, section 3 describes the characteristics of contextualized learning tasks that we seek to create. The approach for the creation of these tasks is then explained in section 4 , and the evaluation of the tasks created with high-school teachers is reported in section 5. Finally, section 6 discusses our lessons learned, and section 7 summarizes the main conclusions of this research and its future research lines. 


\section{Related work}

In the last few years, several authors proposed applications that promote learning in non-formal scenarios by suggesting tasks that are relevant in specific contexts [28]. Typically, a contextualized learning task is composed by a textual description (e.g., "compare the facade of Burgos Cathedral and Leon Cathedral"), one or several supporting multimedia resources (e.g., an image of the facade of Leon Cathedral), and a description of the context where this task is relevant (e.g., a learner who studies Gothic art at a high school and is located next to Burgos Cathedral). Ubiquitous learning applications have to deal with the common problem of authoring such contextualized tasks. But manual authoring of contextualized tasks is tedious and time-consuming and, as a result, not easy to scale. Moreover, when learning contexts refer to specific local physical spaces (e.g., monuments, museums or parks) -as it is commonly the case in ubiquitous learning [18]-, it may not be interesting for a publishing company to offer contextualized learning since this will limit their audience to learners physically close to these contexts.

A possible solution to these problems is to crowdsource the creation of contextualized learning tasks. This way, these proposals obtain a wider variety of tasks of different quality that represent authentic use of language, and they give the quality control to the community of users [27]. An interesting example is SmartZoos [37], where zoo workers create a collection of contextualized tasks. Later on, teachers select a set of these tasks to create "trails" that their students perform when visiting the zoo. Another example is [39], where teachers create and share ubiquitous learning resources (e.g. images, e-books, 3-D models...) that are used and evolved by students. Finally, we can name several applications (see, e.g., [9]) where learners create and/or relate media documents to specific contexts where they may be relevant, thus building a knowledge base of contextualized learning resources. All these preliminary demonstrators crowdsource the maintenance of a learning task dataset. However, all these strategies to crowdsource such a dataset are still burdensome [9, 39], as it is establishing their relationship to formal learning contexts. These applications also require a large community of content creators, which is difficult to recruit if there are no immediate incentives. Finally, applications that support users in the manual creation of tasks suffer from the wellknown problems of annotation quality and consistency [27]. All these problems hinder the scalability of this approach to maintain contextualized learning tasks.

Several authors proposed to automatically create learning resources, tasks or evaluation items. Compared to manual creation of learning tasks, this approach is more efficient, as it reuses already-created datasets to generate more content; and more scalable, as the same procedure can be applied to create additional tasks.

Researchers explored two alternative sources for creating these tasks [2, 1]: unstructured text and ontologies. When creating tasks out of unstructured text researchers apply natural language processing techniques. However, the task they generate are typically superficial test questions that require information that is explicitly stated in the text. This is because it is difficult to infer implicit relationships out of unstructured text. This drawback is avoided when using an ontology as a source for creating questions automatically as it defines explicit relationships between its concepts [2,1].

There are ontologies with potential educational value in many domains even if these ontologies were not generated for educational purposes $[3,2]$. Hence, they have to face the problem of extracting the educational value of the ontology to create questions. This is typically done using templates, which consist of two parts: a filter that selects a subset of the entities in the ontology; and a constructor that defines the surface structure of the question, which will be completed out of the entity parameters. Many of these ontology-based proposals create Multiple Choice Questions (MCQs) [1, 8]. For example, [24] created a dataset of MCQs for the medical domain. Another example is [3], where two domainspecific ontologies about History and Arabic Language were exploited to automatically create MCQs.

These proposals take advantage of semantic reasoners to extract implicit relationships among concepts in the ontology [1, 8, 42]. Nonetheless, even if tasks are obtained automatically, the creation and maintenance of the ontology remains a problem. These tasks are restricted to the domain that the ontology covers (e.g., out of a medical dataset or ontology it is only possible to create tasks related to medicine). In addition, current proposals do not promote higher-level thinking since the tasks typically ask only for factual knowledge $[3,8,22]$. Their support for non-formal learning is also limited, as the tasks are not related to any physical context.

A possible solution to overcome these drawbacks is to exploit the open datasets available on the Web of Data [16]: instead of gathering knowledge from a self-maintained dataset, learning tasks could be created out of the myriad of LOD available on the Web. In fact, in a prior study we followed this same approach to create hundreds of thousands of MCQs about seven different domains in Spanish and English for a trivia game called Clover Quiz [35]. Despite these scalability benefits, LOD has not been deeply explored for the automatic creation of learning resources out of them $[36,20]$; but some examples can still be found [22]. One interesting pioneer study is [40], where DBpedia ${ }^{1}$ is used to populate local datasets that are later on used for programming exercises. Others exploit DBpedia to automatically generate questions [11, 12] or MCQs [7] that are later on assessed in classroom settings. However, all these proposals share some common shortcomings: first, they extract data from a single data source (mainly DBpedia, but also Wordnet ${ }^{2}$ [22]), thus not fully exploiting the potential of LOD; second, they only create tasks to assess factual knowledge (mainly MCQs, but also short free-text questions [22]), thus limiting the pedagogical potential of the proposals [12]; third, they do not relate the generated questions to the physical contexts where they may be relevant, thus hindering their use in contextaware ubiquitous learning applications.

\footnotetext{
1 https://wiki.dbpedia.org/

2 https: //wordnet.princeton. edu
} 
Supporting contextualized learning with LOD

\begin{tabular}{lll}
\hline ID & Task description & Context \\
\hline \hline T1 & $\begin{array}{l}\text { Which is the style of this Hermitage? Find another monument of the same } \\
\text { style nearby and reflect why there are several monuments of this style so close }\end{array}$ & $\begin{array}{l}\text { Hermitage of La Lugareja; Know the } \\
\text { historical reasons of a construction }\end{array}$ \\
\hline \multirow{2}{*}{ T2 } & $\begin{array}{l}\text { Take a photo of the front door. You will find two sculptures that represent the } \\
\text { main economical activities in Valladolid at the end of XIX Century: the industry } \\
\text { and the agriculture }\end{array}$ & $\begin{array}{l}\text { Train station of Valladolid; Know the } \\
\text { characteristics of the bourgeoisie } \\
\text { in Valladolid }\end{array}$ \\
\hline E1 & Can you find modillions or brackets in this church? If you do, take a photo of them & Church of St. Thomas (Salamanca) \\
\hline E2 & $\begin{array}{l}\text { Can you describe the rib vault of the Cathedral? Enumerate the differences you find } \\
\text { with a barrel vault (display an image of a barrel vault) }\end{array}$ & Cathedral of Leon \\
\hline
\end{tabular}

Table 1

Four (out of 84) examples of contextualized learning tasks proposed by teachers (IDs "T") and TEL experts (IDs "E").

\section{Requirements for contextualized learning tasks about historical buildings}

We propose an approach that goes beyond the limitations mentioned in section 2. Our aim is to gather data from several open datasets available on the Web to semi-automatically generate contextualized learning tasks using a template-based method [1, 3, 22]. These tasks should not only assess factual knowledge but also higher-level thinking. They should also state the characteristics of the context where they may be relevant. This approach can potentially be applied to different learning domains (e.g., Forestry, History or Art), different educational levels (e.g., primary, secondary or higher education), different locations, and different languages. As a pilot to explore the approach, we applied it to create contextualized learning tasks about History of Art for secondary education in the Spanish region of Castile and Leon.

We extracted the requirements of the tasks by (i) studying the ubiquitous learning literature [14, 18, 28]; (ii) analyzing other learning applications that offer contextualized learning tasks (e.g., [9, 37, 39]); (iii) interviewing eight teachers of History of Art from three high schools in Castile and Leon; and (iv) collecting 84 examples of informal and contextualized learning tasks (competency questions, in computer science jargon) proposed by these teachers and 13 experts in TEL from a university of Castile and Leon. As the tasks are meant to be used by Spanish students, they were created in Spanish language ${ }^{3}$. Teachers proposed a total amount of 33 tasks (mean of tasks proposed per teacher is 3.38, with a standard deviation of 3.20) and TEL experts proposed 51 (mean 4.77, standard deviation 0.6). Table 1 shows four examples of the tasks collected. The analysis of the literature, the interviews and the tasks will be useful to define which data we should gather from the Web of Data, how to structure the data we gathered, and how to define templates to automatically create tasks out of this data.

The tasks of the ubiquitous learning applications analyzed have a similar structure. They include a textual description of the task and, optionally, a set of multimedia resources (e.g., an image) to support it. The tasks also include some data to define the context where they may be rele-

\footnotetext{
${ }^{3}$ For readability purposes, the terms in Spanish are translated into English in this document.
}

vant. The most important contextual aspects are time and location [18]; while environmental conditions and learner's physiological and personal data may also be relevant in some specific domains [18].

The analysis of the 84 learning tasks collected from teachers and TEL experts helped us identify the characteristics of contextualized learning tasks for the domain of History of Art in Castile and Leon. All these tasks can be considered informal not only because they are meant to be carried out in an informal learning space (e.g., a square or a church), but also because they are integrated in the student's daily routine, they promote the inductive process of experience, reflection and action, and they are influenced by chance [25]. We analyzed these tasks taking into account different features, as summarized in Table 2. There are differences between the tasks proposed by teachers and those proposed by experts. This is because teachers proposed tasks according to their own teaching experience, while TEL experts proposed theoretically-grounded tasks similar to others in the literature. Next, we provide further details:

- Supporting media: We can see that all the tasks proposed include a text that explains the task to be done. Additionally, some of them include other supporting media, such as images or videos (e.g., T2 in Table 1).

- Outcome: Most of the tasks propose students to create resources, either writing a text (e.g., T1, E2), taking a photo (e.g., T2, E1), recording a video, or drawing a map. In four cases the task invites the learner to visit a monument or provides further information about it, but it does not ask the learner to create any resource. In three other cases the task proposes MCQs to be answered.

- Number of entities: Most of the tasks were related to the characteristics of a building (e.g., T2, E1, E2); while almost all the remaining ones were related to two buildings (e.g., E1). In three cases the tasks were related to three entities or more.

- Themes covered: Most of the tasks are related to the architectural characteristics of a building (e.g., T1), or some elements inside it (e.g., E1, E2). Others are related to the socio-cultural aspects in which a particular 
Supporting contextualized learning with LOD

\begin{tabular}{|c|c|c|c|c|c|}
\hline & Type & TE & Experts & Tea & chers \\
\hline \multirow{3}{*}{$\begin{array}{l}\text { Supporting } \\
\text { media }\end{array}$} & Text & 51 & $100 \%$ & 33 & $100 \%$ \\
\hline & Image & 2 & $4 \%$ & 5 & $15 \%$ \\
\hline & Video & 0 & $0 \%$ & 3 & $9 \%$ \\
\hline \multirow{6}{*}{ Outcome } & Text & 36 & $71 \%$ & 15 & $45 \%$ \\
\hline & Photo & 18 & $35 \%$ & 15 & $45 \%$ \\
\hline & None & 0 & $0 \%$ & 4 & $12 \%$ \\
\hline & MCQ selection & 1 & $2 \%$ & 2 & $6 \%$ \\
\hline & Map & 1 & $2 \%$ & 0 & $0 \%$ \\
\hline & Video & 0 & $0 \%$ & 1 & $6 \%$ \\
\hline \multirow{3}{*}{$\begin{array}{l}\text { Number of } \\
\text { entities }\end{array}$} & One & 47 & $92 \%$ & 24 & $73 \%$ \\
\hline & Two & 2 & $4 \%$ & 8 & $24 \%$ \\
\hline & More than two & 2 & $4 \%$ & 1 & $3 \%$ \\
\hline \multirow{4}{*}{$\begin{array}{l}\text { Themes } \\
\text { covered }\end{array}$} & Building charac. & 48 & $94 \%$ & 21 & $64 \%$ \\
\hline & Historical events & 2 & $4 \%$ & 5 & $15 \%$ \\
\hline & Social aspects & 1 & $2 \%$ & 5 & $15 \%$ \\
\hline & Other & 0 & $0 \%$ & 2 & $6 \%$ \\
\hline \multirow{6}{*}{$\begin{array}{l}\text { Bloom's } \\
\text { Taxonomy }\end{array}$} & Remember & 25 & $49 \%$ & 18 & $55 \%$ \\
\hline & Understand & 5 & $10 \%$ & 6 & $18 \%$ \\
\hline & Apply & 4 & $8 \%$ & 1 & $3 \%$ \\
\hline & Analyze & 17 & $33 \%$ & 4 & $12 \%$ \\
\hline & Evaluate & 1 & $2 \%$ & 3 & $9 \%$ \\
\hline & Create & 0 & $0 \%$ & 1 & $3 \%$ \\
\hline \multirow{4}{*}{$\begin{array}{l}\text { Contextual } \\
\text { aspects }\end{array}$} & Physical location & 51 & $100 \%$ & 33 & $100 \%$ \\
\hline & Prior knowledge & 0 & $0 \%$ & 12 & $36 \%$ \\
\hline & Course & 0 & $0 \%$ & 6 & $18 \%$ \\
\hline & Transversal comp. & 0 & $0 \%$ & 2 & $6 \%$ \\
\hline
\end{tabular}

Table 2

Characteristics of 84 contextualized learning tasks about History of Art in Castile and Leon. 51 tasks were proposed by TEL experts and 33 by teachers. Note that a single task may include several supporting media, may ask several outcomes and/or may be related to several themes.

building was built (e.g., T2), or the historical events that happened in those places.

- Bloom's Taxonomy: the Bloom's Taxonomy [6] is a well-known six-level scale for hierarchically ordering cognitive skills, which has been used by several authors for the classification of automatically-created learning tasks $[12,38]$. We realized that most of them were related to the levels of "remember" (the task intends to help the student remember the terminology; e.g., T2, E1) or "analyze" (like in tasks where the goal is to determine the style or the characteristics of a monument; e.g., T1, E2). Nonetheless, the other four levels of the taxonomy were also represented in the tasks analyzed.

- Contextual aspects: the contexts related to these tasks were mainly defined by the physical location of the learner (e.g., T1, T2, E1, E2). Teachers also underlined that some tasks should only be proposed once some topics are covered in the classroom (e.g., T1, T2) or to learners who are in a specific course (so they are expected to know some topics). In two cases teachers also mentioned transversal competences, such as being able to search for information online.

The contextualized learning tasks that we aim to semi- automatically create should cover a wide range of the tasks proposed by teachers and TEL experts. Thus, they should include a textual description and, optionally, a supporting image. Further, they should inform learners about monuments or invite them to create resources out of their visits. The tasks may be related to one or two buildings and should mainly focus on their characteristics. These tasks should also cover the six levels of the Bloom's Taxonomy. Finally, their context should be defined by the learner's physical location and his prior knowledge.

Finally, we also used the task analysis to create a domain taxonomy (see Figure 1) by structuring the types of physical entities mentioned by teachers and TEL experts. This taxonomy is congruent with the Wikipedia categories. For the sake of clarity, in the present paper the prefixes are kept in a contracted form. To see their expanded version, please see Table 9 in Appendix A.

\section{Generation of contextualized learning tasks}

The process of semi-automatic generation of contextualized learning tasks out of the Web of Data is depicted in Figure 2. It includes three main steps: the selection of Open Data sources (subsection 4.1); the extraction of data to create a local domain dataset (subsection 4.2); and the generation of learning tasks out of this dataset (subsection 4.3). The next subsections provide further details of how each step is applied for the domain of History of Art in Castile and Leon.

\subsection{Data source selection}

Our first step for the data extraction is to select a set of Open Data sources that include information about historical buildings in Castile and Leon. We select the Spanish version of DBpedia $^{45}$, as it mirrors the Spanish Wikipedia, which includes information about historical buildings. Note that even if the English version of DBpedia includes more information about historical buildings in general terms, when looking for the local knowledge about a region of Spain, the Spanish version is richer. Indeed, other researchers also used local versions of DBpedia to create quizzes about their local knowledge [7, 26]. Another source of our interest is Wikidata $^{6}$, which offers descriptions of historical buildings that include their geolocalization. Both DBpedia and Wikidata are linked datasets that offer an SPARQL interface to access the data (5-star datasets, according to Tim Berners Lee's classification [5]). Finally, we select the dataset of buildings declared as Assets of Cultural Interest ${ }^{7}$ published by the regional government of Castile and Leon in its Open Data Portal (JCYL). This dataset is offered as a downloadable JSON file (3-stars).

These datasets provide descriptions of most of the historical buildings where the tasks analyzed in section 3 are con-

\footnotetext{
${ }^{4}$ http://es.dbpedia.org

${ }^{5}$ From now on, when mentioning 'DBpedia' we will refer to the Spanish version of DBpedia.

${ }^{6}$ https://www.wikidata.org/wiki/Wikidata:Main_Page

${ }^{7}$ https://datosabiertos.jcyl.es/web/jcyl/set/es/cultura-ocio/ bienes-inmuebles/1284872768044
} 


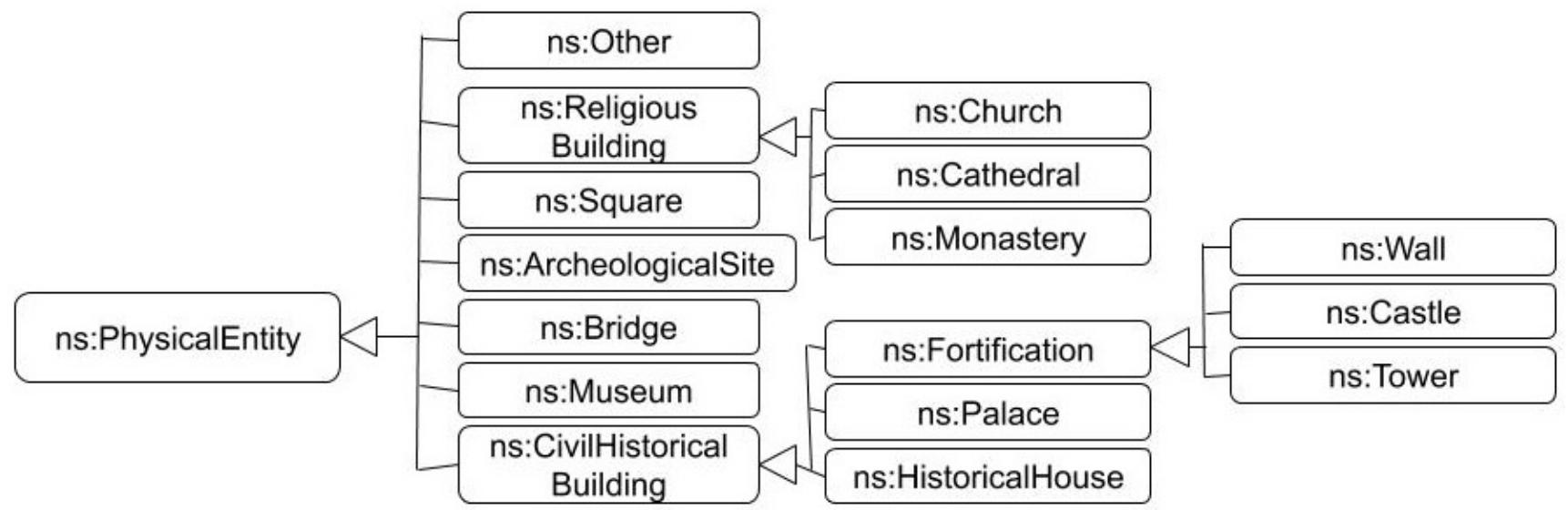

Figure 1: Domain taxonomy for historical buildings of Castile and Leon. It is based on the analysis of 84 contextualized learning tasks proposed by 8 high-school teachers and 13 TEL experts in educational technology.

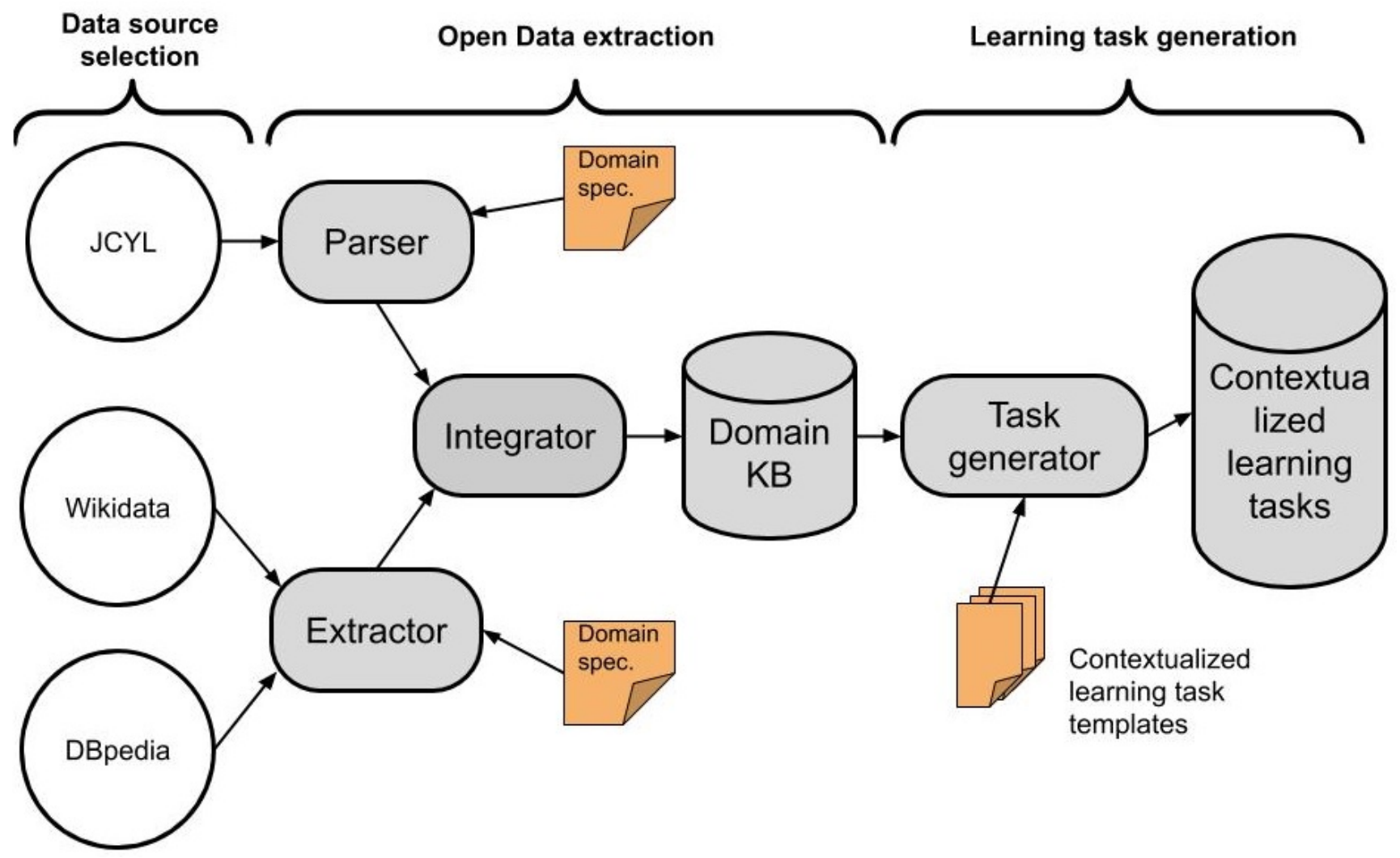

Figure 2: Overview of the contextualized learning task generation process. Elements in white are external; elements in grey could be reused for other domains; elements in orange should be created for each domain.

textualized. Only 9 out of 84 tasks mentioned buildings that are not covered. This is due to the fact that these datasets do not contain descriptions of many civil buildings or city areas that can still be used to learn History of Art (e.g., museums or streets); but they do contain descriptions of all the historical and religious buildings where the analyzed tasks are contextualized. They provide information such as their name, the type of building, an image, the location, a textual abstract or some of its architectural and ornamental elements.

\subsection{Open Data extraction}

Once the sources are selected, we proceed with the extraction phase. The goal here is to gather the data of our interest and integrate it to create a Domain Knowledge Base (Domain KB, see Figure 2).

There are three main alternatives to gather Open Data [16, chap. 6]: crawling the Web of Data, data dumps, and live queries. We discarded the live queries solution because of its technical complexity -especially when dealing with multiple data sources [16, chap. 6]-, and the stringent require- 
ments of the interactive applications that may exploit the learning tasks generated. The other two solutions were employed depending on the characteristics of the data source we gathered data from. The list of monuments of Castile and Leon published in the Open Data portal of the Regional Government of Castile and Leon is offered as a 3-star JSON or XML file. So the only possible way to access its data is dumping the whole dataset. On the other hand, DBpedia and Wikidata offer 5-star Linked Open Data that can be queried through their SPARQL endpoints and can be downloaded as data dumps. From these sources we only need descriptions of monuments and public spaces of Castile and Leon, which represent a small subset of the data available in these two sources. Hence, we crawled these datasets submitting queries to their SPARQL endpoints and following the links that relate their concepts.

The Domain KB should contain the data needed to create Contextualized learning tasks, according to the requirements analyzed in section 3. Hence, the entities in the Domain KB are members of the classes in the taxonomy shown in Figure 1. In order to create the set of contextualized learning tasks, the entities extracted are annotated with descriptive data through properties (e.g., rdfs:label, dbo:style), supporting media (e.g., dbp:image), and further information to provide context (e.g., skos: related, geo:long, geo:lat).

The scripts used to access the WoD depend on the way these sources can be accessed. We developed an Extractor to access 5-star datasets. It firstly extracts entities from DBpedia SPARQL endpoint and relates them to the appropriate class in the domain taxonomy. The Domain specification file includes the information needed to build the SPARQL queries and to relate the results to the taxonomy used in the Domain KB. For this purpose we use the Wikipedia categories. This lets us restrict the entities according to their type and their context. As an example, we retrieve entities related to ns: Castle out of the Wikipedia category "Castles of Castile and Leon"8. The query submitted to DBpedia is shown in Listing 1 (all SPARQL queries are paginated because they may provide many results, as recommended in [35].).

Listing 1: SPARQL query for retrieving entities of ns: Castle select ?entity where

?entity dcterms: subject ?S.

?S skos:broader $\{, 5\}$

dbcat: Castillos_de_Castilla_y_León

In other cases we use the dbo:buildingType relationship, selecting only those entities located in one of the nine provinces of Castile and Leon; as an example, Listing 2 depicts the query for retrieving entities related to ns:Monastery.

Listing 2: SPARQL query for retrieving entities of ns: Monastery select ?X where \{

?X dbo:building Type db: Monasterio.

?X dbo: location ?mun

$\{\{$ ?mun dbo: areacode $" 05 "\}$

UNION \{?mun dbo: areacode "09"\}

\footnotetext{
${ }^{8}$ dbcat:Castillos_de_Castilla_y_León
}

UNION $\{$ mun dbo: areaCode $" 24 "\}$
UNION $\{$ mun dbo: areaCode $" 34 "\}$
UNION $\{$ mun dbo:areaCode $" 37 "\}$
UNION $\{$ mun dbo: areaCode $" 40 "\}$
UNION $\{$ mun dbo:areaCode $" 42 "\}$
UNION $\{$ mun dbo: areaCode $47 "\}$
UNION $\{$ mun dbo: areaCode $49 "\}\}\}$

In some cases the relationships between DBpedia concepts and the Domain taxonomy are one-to-one; for example, ns:Castle is only related to dbcat:Castillos_de_Castilla_ y_León. In other cases, the relationships are one-to-many; for example, ns:Church is related to dbcat:Iglesias_románicas_ de_Castilla_y_León, dbcat: Iglesias_góticas_de_Castilla_y_ León and others.

In a second step the Extractor gathers from DBpedia the corresponding property values for every entity found. The Domain specification file includes one-to-one mappings between properties in the DBpedia ontology and properties in our ontology. As we are working in a very specific domain, the structure of DBpedia is more regular than when dealing with multiple domains [35]. The Extractor uses these relationships to build SPARQL queries and submit them to DBpedia. As an example, Listing 3 depicts the query for retrieving the value for the property $\mathrm{dbp}$ : image of entity2 (see Table 3).

Listing 3: SPARQL query for retrieving the dbp : image of entity2 in Table 3

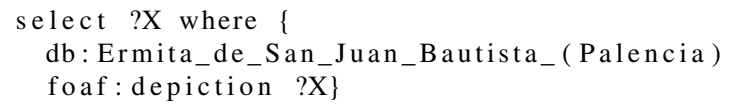

The Extractor exploits owl: sameAs properties to find additional information of entities in other datasets. Specifically, DBpedia includes owl: sameAs links to Wikidata, so the Extractor accesses the Wikidata endpoint to gather geolocation data of the entities found (geo: long, geo: lat).

With respect to the JCYL dataset, we developed a Parser that translates source data into entity descriptions annotated with our ontology. This is done with another Domain specification file that maps source codes to the historical building types defined in our ontology. The Domain specification file also includes one-to-one relationships between the vocabulary used in such file and the ontology of the Domain KB. This way, the entities from different sources are described using a unified vocabulary.

Then, the Integrator is in charge of merging the data retrieved from different sources. The first step for the data integration is the Identity Resolution [16, chap. 6], i.e. detecting if two descriptions of buildings from different sources refer to the same building or not. We assumed that if the positions reported in the description of two buildings are less than 111 meters ( 0.001 grades), they are probably referring to the same building.

This identity resolution is done in three steps. First, the Integrator clusters geolocalized entities in close proximity. In this step we obtained 740 clusters with more than two entities. These are candidates of descriptions referring to the same building. Second, we manually selected the candidates 
Supporting contextualized learning with LOD

\begin{tabular}{|c|c|c|c|c|c|}
\hline Property & Source & entity0 & entity1 & entity 2 & entity3 \\
\hline \multirow{2}{*}{ rdfs:label } & DBpedia & $\begin{array}{l}\text { "Castle of } \\
\text { La Mota" }\end{array}$ & & $\begin{array}{l}\text { "Hermitage of Saint John } \\
\text { the Baptist (Palencia)" }\end{array}$ & "Church of Saint Francis (Palencia)" \\
\hline & JCYL & $\begin{array}{l}\text { "Castle of } \\
\text { La Mota" }\end{array}$ & $\begin{array}{l}\text { "Colegio de } \\
\text { San Gregorio" }\end{array}$ & $\begin{array}{l}\text { "Church of Saint John the Baptist } \\
\text { - Villanueva del Río" }\end{array}$ & "Church-convent of Saint Francis" \\
\hline \multirow{2}{*}{ rdf:type } & DBpedia & ns:Castle & & ns:Church & ns:Church \\
\hline & JCYL & ns:Castle & ns:Other & ns:Church & ns:Church \\
\hline \multirow{2}{*}{ dbo:style } & DBpedia & & & "Romanesque" & \\
\hline & JCYL & "Mudéjar" & "Gothic" & "Romanesque" & "Gothic" \\
\hline dbp:image & DBpedia & $\begin{array}{l}\text { dbf:Castillo de la } \\
\text { mota por chefo.jpg }\end{array}$ & & dbf:San_Juan02.JPG & $\begin{array}{l}\text { dbf:Iglesia_de_San_Francisco } \\
\text { (Palencia)._Fachada.jpg }\end{array}$ \\
\hline skos:related & DBpedia & "Allure", "Machicolation"... & & "Arquivolt", "Column"... & "Segmental arch", "Coffered ceiling"... \\
\hline \multirow{2}{*}{ geo:long } & Wikidata & -4.90833 & & -4.52449 & -4.53194 \\
\hline & JCYL & -4.90854 & -4.723799 & -4.524495 & -4.532018 \\
\hline \multirow{2}{*}{ geo:lat } & Wikidata & 41.3089 & & 42.0076 & 42.0114 \\
\hline & JCYL & 41.30917 & 41.657122 & 42.007653 & 42.011457 \\
\hline
\end{tabular}

Table 3

Main properties of four sample entities gathered from the Web of Data.

\begin{tabular}{|c|c|c|c|c|c|}
\hline Type & DBpedia & Wikidata & JCYL & Intersection of the 3 sources & TOTAL \\
\hline ns:Church & 551 & 551 & 606 & 213 & 944 \\
\hline ns:Cathedral & 5 & 5 & 10 & 3 & 12 \\
\hline ns:Monastery & 162 & 162 & 106 & 56 & 212 \\
\hline ns:Square & 14 & 14 & 9 & 1 & 22 \\
\hline ns:ArcheologicalSite & 95 & 95 & 142 & 27 & 210 \\
\hline ns:Bridge & 38 & 38 & 16 & 7 & 47 \\
\hline ns:Museum & 77 & 77 & 12 & 12 & 77 \\
\hline ns:Wall & 30 & 30 & 29 & 3 & 56 \\
\hline ns:Castle & 132 & 132 & 154 & 50 & 236 \\
\hline ns:Tower & 12 & 12 & 23 & 6 & 29 \\
\hline ns:Fortification & 204 & 204 & 212 & 65 & 351 \\
\hline ns:Palace & 98 & 98 & 109 & 16 & 191 \\
\hline ns:HistoricalHouse & 0 & 0 & 24 & 0 & 24 \\
\hline ns:Other & 0 & 0 & 89 & 0 & 89 \\
\hline TOTAL & 1224 & 1224 & 1324 & 370 & 2178 \\
\hline
\end{tabular}

Table 4

Number of descriptions of entities retrieved from DBpedia, Wikidata and JCYL. Note that all the descriptions retrieved from DBpedia were enriched with data from Wikidata.

that were actually referring to the same building, choosing a total amount of 370 buildings. This distinction was done according to their rdfs: label value. So we assume that if the reported geolocation and the reported label of two descriptions are similar, they are actually referring to the same building (examples are entity0, entity 2 and entity 3 in Table 3). A final integration step aggregates the data from different sources. The Integrator explicitly states the origin of each data to guarantee the Provenance Tracking [16, chap. 6].

Table 3 shows some parameters of four entities described in the Domain KB. All in all, our approach is able to create a Domain KB of 2178 historical buildings of Castile and Leon. 1224 of them were retrieved from DBpedia and Wikidata, 1324 from the Open Data Portal of Castile and Leon, and 370 from the three sources. Table 4 includes the number of descriptions gathered, their provenance and their relationship to the Domain Taxonomy.

\subsection{Learning task generator}

Upon obtaining the Domain KB, the Task generator is in charge of generating a set of Contextualized learning tasks.
This component relies on the use of templates, which is the most common approach for the automatic generation of learning tasks [22]. The Task generator is a script that takes as input a set of Contextualized learning task templates and exploits the semantic relationships in the Domain KB to generate a set of Contextualized learning tasks in RDF.

For each template, the Task generator should select a subset of the entities in the Domain KB and then apply some constructors that consist of fixed text and some placeholders that are populated with entity data [22]. Therefore, as the basis of its structure, each template should include a filter to select the entities from the Domain KB, and a constructor to create the tasks.

More specifically, our template structure is based on our previous work in Cover Quiz [35]. Clover Quiz automatically built more than $200 \mathrm{~K}$ questions of multiple domains from the Web of Data, showing that its template structure is flexible and adaptable to many domains. Nonetheless, we improve the maintenance of the set of templates by enabling the inclusion of multiple constructors in a single template. Thus, we need a lower number of more-maintainable templates to create the same tasks. 
The constructor structure is defined according to the structure of the Contextualized learning tasks, which is based on our requirements analysis (see Table 2). Each task includes a textual description of the task, the type of expected outcome, its relationship to Bloom's Taxonomy and, optionally, an image. The context of the task is defined by three properties: latitude and longitude, to specify the physical location, and a set of related topics. Related topics can be explicit in the constructor, but they are also obtained from the topics included for each entity in the Domain KB (see Table 3).

Regarding the filter structure, the Task generator manages three types of Contextualized learning task templates. These types differ in the structure of their filters. Next, we provide further details about each type.

The first type of Contextualized learning task templates are single-entity templates; Listing 4 shows an example. In this example, the filter selects the entities that only have one style (some historical monuments are described with more than one style) and this style is either "Gothic" or "Romanesque". Then, it applies two constructors that create and localize the task in the place where the monument is and relate the task to the "analyze" level of the Bloom's Taxonomy. Both constructs generate a written text as output. They also specify a text to define the task and use an image to support it. When applied to entity1 (Table 3), the first constructor creates the task displayed in Figure 3.

Listing 4: Example of a single-concept template including two constructors (simplified version)

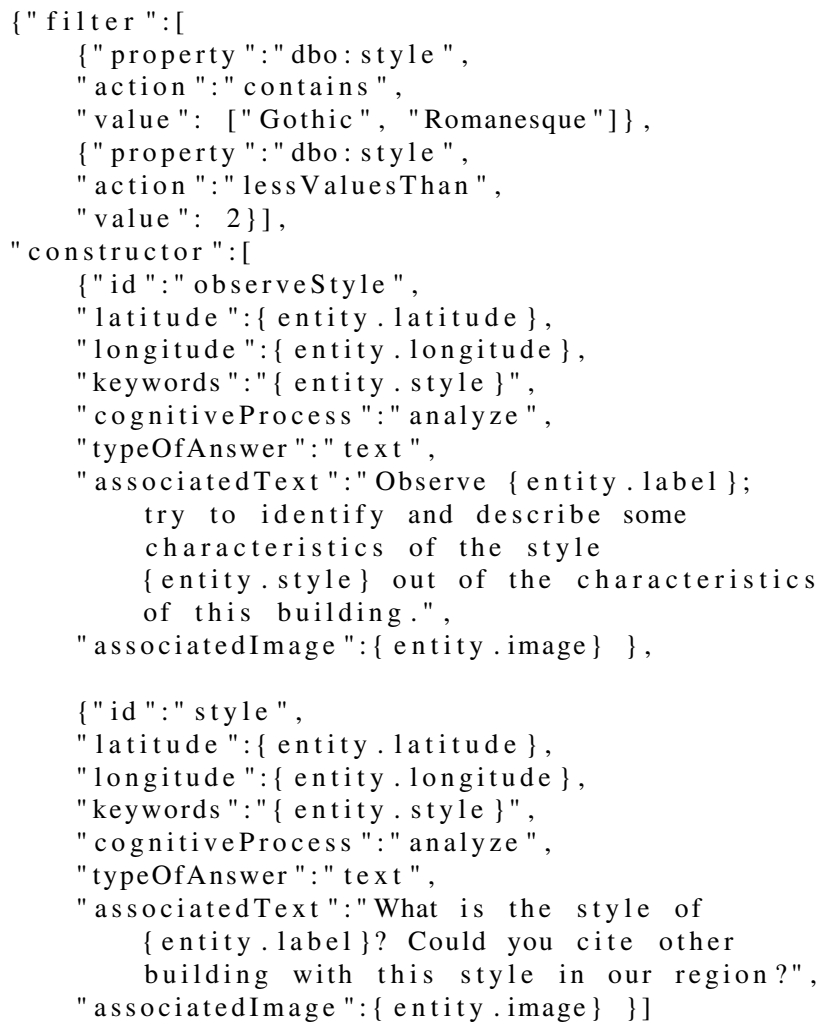

The second type of Contextualized learning task templates are two-entity templates; Listing 5 shows an example. In this example, the filter selects two buildings, one of Gothic style and one of Romanesque style, that are in a close distance (less than 0.01 UTM grades, $1.11 \mathrm{~km}$., in both latitude and longitude). The constructor contextualizes the task in the surroundings of the first building. It also defines a textual description of the task and an image to support it. When applied to entity 2 and entity 3 , it creates the task displayed in Figure 4.

Listing 5: Example of a two-concept template including one constructor (simplified version)

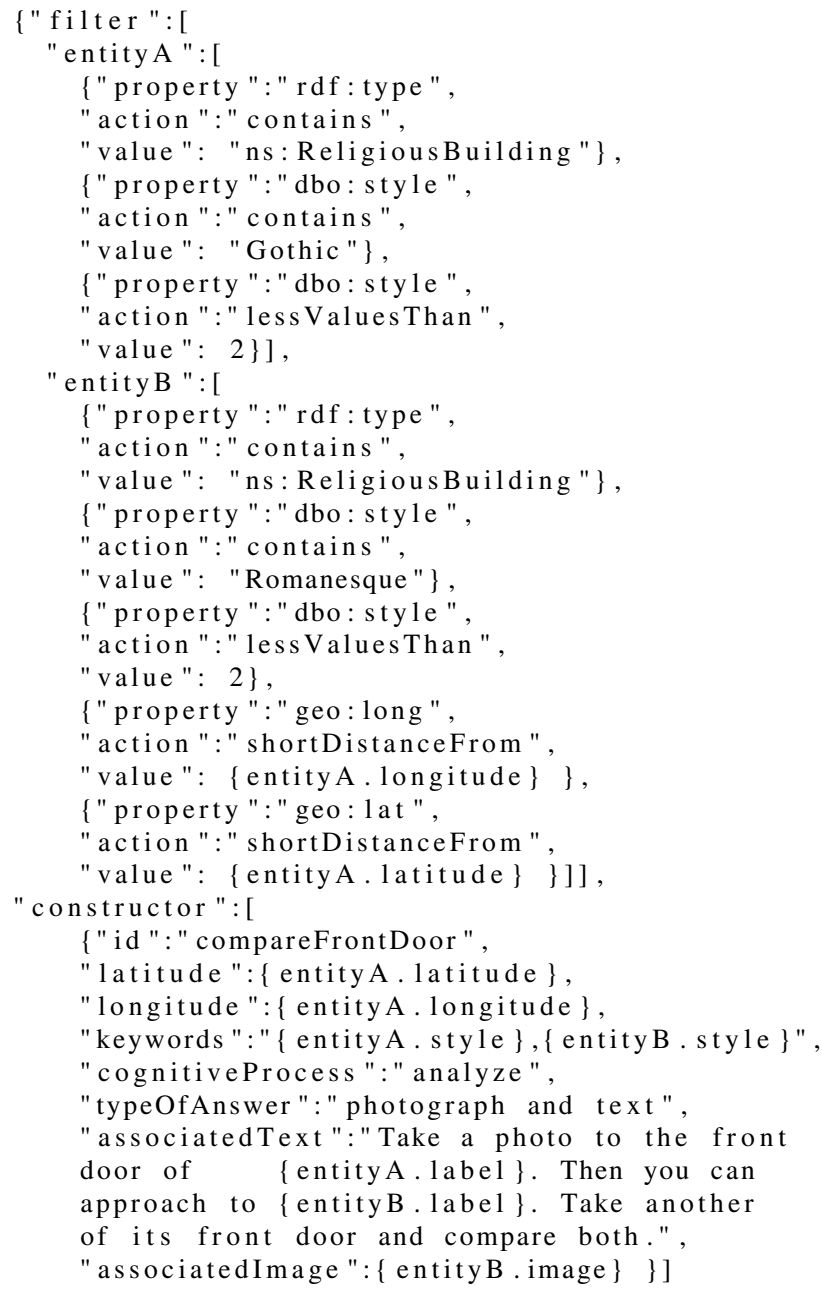

The third type of Contextualized learning task templates are list templates; Listing 6 shows an example. In this example, the template iterates over the elements of the list "Military architectural elements". For each element, the filter selects the fortifications that are related to such element. The constructor contextualizes the task in the location of the building and presents a text that defines the task. When iterating over the element "machicolation" and the filter applied to entity0, it creates the task displayed in Figure 5.

Listing 6: Example of a list template including one constructor (simplified version)

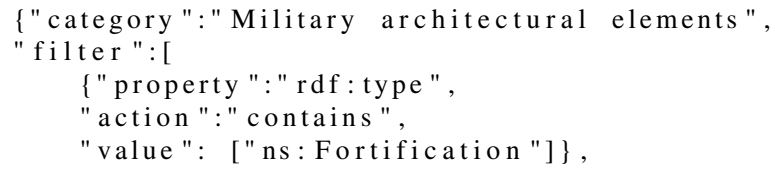




\begin{tabular}{lcc}
\hline & Templates & Tasks obtained \\
\hline \hline Single entity & 18 & 8242 \\
\hline Two entities & 6 & 6760 \\
\hline List & 8 & 1219 \\
\hline \hline TOTAL & 32 & 16221 \\
\hline
\end{tabular}

Table 5

Number of templates, constructors and tasks.

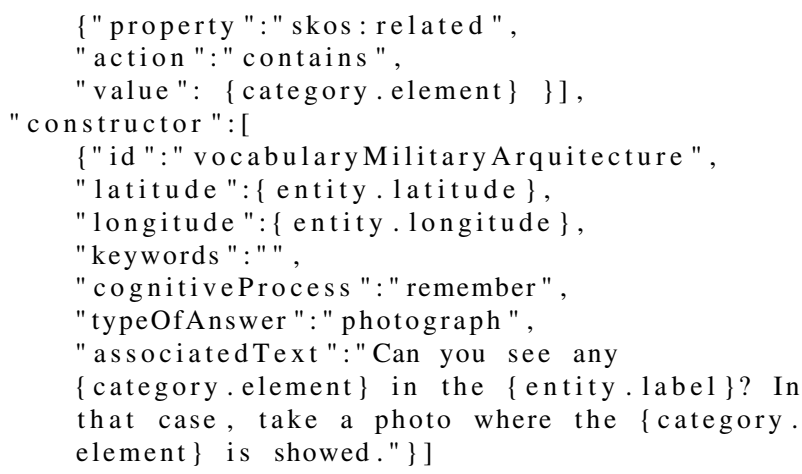

List templates require the generation of the lists of elements to be iterated. These lists are automatically created out of the Wikipedia categories. For example, the list "Military architectural elements" is obtained out of the category "Terms of military architecture" 9 .

All these Contextualized learning task templates are processed by the Task generator. Its implementation is also based on our previous work in Cover Quiz [35]. We used Javascript and the underscore.js library ${ }^{10}$, which allows functional programming [10]. This let us write high-level concise code that is easy to read and maintain.

We created 32 contextualized learning task templates to cover all the tasks proposed by the teachers and the TEL experts (note that some tasks proposed by several teachers can be covered by the same template and constructor). With these 32 templates we obtain 16221 contextualized learning tasks. Table 5 summarizes them.

The Contextualized learning tasks created are published back as Linked Open Data. We use Virtuoso ${ }^{11}$ for this purpose, a well-known server to publish Linked Open Datasets distributed with an open license. We provide a SPARQL endpoint to retrieve the tasks generated, which can be accessed at: https://casuallearn.gsic.uva.es/sparql The task namespace is https://casuallearn.gsic.uva.es/ Figures 3, 4 and 5 show mock-ups of a potential application that consumes the tasks offered.

\section{Evaluation}

In previous sections, we described how a knowledge base of contextualized educational learning tasks. As it is derived with an explicit use in mind, its quality should be determined by the "fitness for use" $[19,41]$. Therefore, in this section

\footnotetext{
${ }^{9}$ dbcat:Términos_de_arquitectura_militar

10 https://underscorejs.org/

$11_{\text {https: //virtuoso.openlinksw.com }}$
}

\section{$\leftarrow$ Casual Learn App}

\section{What is the style of Colegio de San Gregorio? Could you cite other buildings with this style in our region?}

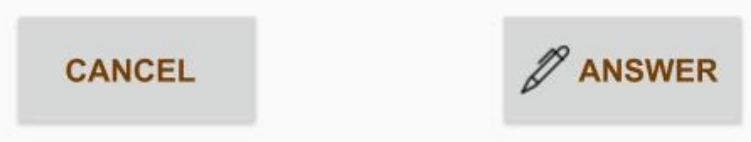

Figure 3: Mock-up of an application displaying a contextualized learning task. This task was obtained with the template described in Listing 4.

we describe an empirical evaluation done to gather initial evidence of the usefulness of the ubiquitous learning tasks generated and their acceptance by the educational community. We carried out an evaluation with teachers, which is the most common evaluation method for automatically-created learning tasks or content [22].

\subsection{Evaluation method}

A total of $16 \mathrm{~K}$ ubiquitous learning tasks have been generated. As the manual evaluation of them all would be very demanding, we selected a subset of them to be assessed by 8 teachers from three high-school institutions of Castile and Leon; 3 of them live in Palencia and 5 of them in Valladolid. All these teachers participated in the task requirement analysis reported in section 3 .

Regarding the tasks assessed, we grouped them according to the template that created them and their relationship to Bloom's Taxonomy. Then we randomly selected 27 tasks (see Table 6) so that they follow a similar distribution to Bloom's Taxonomy as those provided by teachers and TEL experts (see Table 2). Note that manual evaluation of learning tasks is very time demanding [22]. This is why learning task evaluation with teachers typically assess a few tens of tasks (see, for example [1, 3, 8]). Nevertheless, the diversity of the tasks selected allow us to cover a wide range of the learning tasks in the dataset.

We carried out a structured interview with each teacher, in which we asked them to assess 10 tasks (so each task is assessed by three different teachers) geolocalized in the province where they live (so it is more likely for them to know the buildings the tasks refer to). For each task, we 
Supporting contextualized learning with LOD

\begin{tabular}{l|cc|cc|cc|cc}
\hline \multirow{2}{*}{ Template } & \multicolumn{2}{|c|}{ Single Entity } & \multicolumn{2}{c|}{ Two Entities } & \multicolumn{2}{c|}{ List } & \multicolumn{2}{c}{ TOTAL } \\
& Palencia & Valladolid & Palencia & Valladolid & Palencia & Valladolid & Palencia & Valladolid \\
\hline \hline Remember & 1 & 1 & 1 & 2 & 2 & 3 & 4 & 6 \\
\hline Understand & 0 & 0 & 1 & 1 & 0 & 0 & 1 \\
\hline Apply & 0 & 3 & 0 & 0 & 0 & 0 & 0 & 3 \\
\hline Analyze & 1 & 2 & 1 & 1 & 1 & 3 & 3 & 6 \\
\hline Evaluate & 1 & 1 & 0 & 0 & 0 & 0 & 1 & 1 \\
\hline Create & 1 & 0 & 0 & 0 & 0 & 0 & 1 & 0 \\
\hline \hline TOTAL & 4 & 7 & 3 & 4 & 3 & 6 & 10 & 17 \\
\hline
\end{tabular}

Table 6

Characteristics of the tasks evaluated.

\section{$\leftarrow$ Casual Learn App}

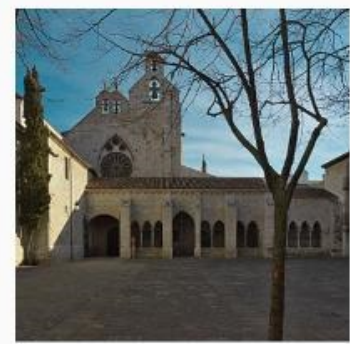

Take a photo to the front door of Saint

John Baptist church. Then you can approach to Saint Francis Church. Take another photo of its front door and compare both

\section{CANCEL}

Figure 4: Mock-up of an application displaying a contextualized learning task. This task was obtained with the template described in Listing 5.

firstly asked them if they knew the place where the task was located and, in case they did not, we proceeded with an "alternative task". These alternative tasks were obtained from the same constructor as the task to be assessed. For each task, we asked them to imagine a 17-year-old high-school student to whom such a contextualized task was assigned. Then, we asked them four Yes/No questions:

1. Is this task significant (i.e., related to the curriculum) for this type of student?

2. Is this task relevant for this student in this location, i.e., will the student learn if he carries out this task in this location?

3. Is the difficulty of the task adequate for this type of student?

4. Would you accept that this task is posed to those of your students who have this profile and in this location?

Besides their affirmative or negative response, teachers could further justify the rationale behind their answers.

\section{$\leftarrow$ Casual Learn App}

\section{Can you see any machicolation in the Castle of La Mota? In that case, take a photo where the machicolation is shown.}

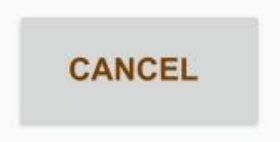

[O] CAMERA

Figure 5: Mock-up of an application displaying a contextualized learning task. This task was obtained with the template described in Listing 6.

\subsection{Results}

Table 7 reports the number of tasks evaluated by teachers positively. The most positive result is that all the teachers would accept that their students carry out any of the tasks proposed. The results of the other three aspects were also very positive as the vast majority of the tasks are evaluated as significant, relevant and having an adequate difficulty. Interestingly, there is no significant difference in the results depending on the task's level of the Bloom's taxonomy. However, some differences can be found depending on the templates that generated the tasks.

The tasks generated out of single-entity templates obtained very positive results. There are some differences in the teachers' perception regarding whether some concepts are related to the high-school curriculum. An example refers to the concepts related to the popular architecture, which all 3 teachers consider as non significant.

Another interesting example is the task: "Look at the characteristics of the Convent of Agustinos Filipinos; try to identify and describe some characteristics of the Baroque 
Supporting contextualized learning with LOD

\begin{tabular}{lcccc}
\hline Templates & Single Entity & Two Entities & List & TOTAL \\
\hline \hline Significance & $28 / 33,85 \%$ & $18 / 21,86 \%$ & $23 / 27,85 \%$ & $69 / 81,85 \%$ \\
\hline Relevance & $32 / 33,97 \%$ & $20 / 21,95 \%$ & $25 / 27,93 \%$ & $78 / 81,96 \%$ \\
\hline Difficulty & $29 / 33,88 \%$ & $16 / 21,76 \%$ & $18 / 27,66 \%$ & $63 / 81,78 \%$ \\
\hline Acceptance & $33 / 33,100 \%$ & $21 / 21,100 \%$ & $27 / 27,100 \%$ & $81 / 81,100 \%$ \\
\hline
\end{tabular}

Table 7

Number of tasks evaluated by teachers positively considering their significance, relevance, difficulty level, and acceptance.

\begin{tabular}{lcccc}
\hline Templates & Single Entity & Two Entities & List & TOTAL \\
\hline \hline \multirow{2}{*}{ Significance } & $0.837(0.716,0.958)$ & $0.622(0.395,0.849)$ & $0.604(0.404,0.804)$ & $0.703(0.604,0.802)$ \\
& Substantial & Fair & Fair & Moderate \\
\hline \multirow{2}{*}{ Relevance } & $0.936(0.868,1)$ & $0.895(0.78,1)$ & $0.828(0.698,0.958)$ & $0.891(0.835,0.947)$ \\
& Almost perfect & Substantial & Substantial & Substantial \\
\hline \multirow{2}{*}{ Difficulty } & $0.769(0.621,0.917)$ & $0.402(0.105,0.699)$ & $0.467(0.212,0.722)$ & $0.585(0.457,0.713)$ \\
& Moderate & Poor & Slight & Fair \\
\hline
\end{tabular}

Table 8

Gwet's AC1 mean, 95\% confidence interval and interpretation of the agreement between teachers when assessing the significance, relevance and difficulty of the tasks.

style out of the characteristics of this building". A teacher mentioned that the Convent of Agustinos Filipinos is of Neoclassic style. The teacher perception is right; however, the Convent description in DBpedia ${ }^{12}$ is erroneous.

The tasks generated out of two-entity templates had similar results. These tasks, in many cases, invite students to compare the characteristics of two nearby buildings or to reflect about the appearance of some buildings with similar characteristics in certain area. Most teachers tend to like this type of questions. But some of them consider that deepening into the local history is out of the high-school curriculum and may be too difficult for the students. For example, two teachers consider too difficult the task depicted in Figure 4.

The tasks generated out of the list templates also obtained very positive results regarding the significance, relevance and acceptance, but not so good regarding the difficulty. The tasks obtained from list templates include in their task descriptions a term from a list, which highly influences the task assessment. For example, a teacher considers the term "barbican" out of the curriculum. More frequently, these terms have an impact on the perception of difficulty. An example is the task "Take a photo of, at least, a nave of the church of Saint Paul". Two teachers consider this task too easy; but they would consider it of adequate difficulty if instead of "nave" the task includes other terms, like "ambulatory" or "transept". This task is also surprising for the teachers because the nave of the church of Saint Paul has nothing special, while its facade is a well-known masterpiece of the Isabelline Gothic style. However, in the descriptions retrieved from the Web of Data there is no semantic relationship that shows the relevance of the elements of a building. Indeed, in its DBpedia description, the church of Saint Paul ${ }^{13}$ is not related to the term "facade"14.

The appearance of other elements made other tasks too difficult. For example, all the teachers consider very difficult the task described as "Find a bell-gable in the church of

\footnotetext{
$12 \mathrm{db}$ : Convento_de_los_Agustinos_Filipinos_(Valladolid)

$13 \mathrm{db}$ : Iglesia_de_San_Pablo_(Valladolid)

$14 \mathrm{db}$ : Fachada
}

Saint Peter and then reflect if you have seen others in buildings of other styles. Why? Which are the characteristics of Romanesque bell-gables?". They do not expect high-school students to know the stylistic differences of bell-gables; but they do expect them to know the differences of other elements. Indeed, all the teachers consider as adequate the difficulty of another task obtained with the same template and described as "Find a rose window in the church of St. Michael and then reflect if you have seen others in buildings of other styles. Why? Which are the characteristics of Gothic rosewindows?".

Table 8 includes the agreement between teachers when assessing the tasks using Gwet's AC1 [15] with 95\% confidence interval (the interpretation of the magnitude of agreement coefficients was made by computing the cumulative membership probabilities of values to the Landis-Koch scale [23]). There is no disagreement regarding the acceptance of the tasks. The other aspects require further explanation.

There is a moderate agreement regarding the significance of the tasks. The disagreement among teachers can be mainly attributed to their interpretation of the curriculum. It should be noted that in Spain there are national and regional educational laws, but schools develop their own educational projects, and teachers contextualize the curriculum according to the students' needs (see [29] for more details). This makes, for example, that not all teachers agree on whether some basic knowledge related to military fortifications (e.g., knowing some terms like "barbican") is part of the curriculum.

In other cases the interpretation of the task by the teachers makes them consider it related to the curriculum or not. As an example, two teachers interpret that the task depicted in Figure 4 asks for a detailed comparison of the characteristics and the iconography of the front door of these two temples; they consider that deepening so much into the local history is out of the secondary-school education curriculum. However, another teacher interprets that this task asks for a comparison between the front door of a Romanesque church and the front door of a Gothic church. Hence, she rated it as 
significant.

There is a fair agreement regarding the difficulty of the tasks. Again, in many cases the source of disagreement is the different interpretation of the tasks between teachers. For example, the same two teachers who consider the task depicted in Figure 4 as not significant also consider it too difficult. In other cases it is the teacher's expertise that makes them differ in their opinion; e.g., the teacher who knew that the Convent of Agustinos Filipinos is of Neoclassic style considered the task too difficult, while the other two teachers consider its difficulty adequate. Finally, other disagreements occur because teachers have different expectations of the students' knowledge. Two teachers consider the task "Take a photo of, at least, a nave of the church of Saint Paul" too easy, as they expect any 17-year-old student to know the term "nave". However, the opinion of another teacher is that the task can still be interesting to brush up the knowledge of some students. In some of these cases the teachers also disagree regarding the relevance of the task, as some of them understand that they are so easy that a student will not learn anything by carrying them out. But there was a substantial agreement regarding the relevance of the tasks.

All in all, we consider the results very positive: $100 \%$ of the tasks would be accepted by the teachers, while most of them are considered as relevant $(96 \%)$, significant $(85 \%)$, and of an adequate difficulty (78\%). Teachers also expressed their surprise when knowing that these contextualized learning tasks were semi-automatically created. They would also like their students to use an application that exploits these tasks.

\section{Discussion}

In this paper we followed an approach to semi-automatically create contextualized learning tasks out of Open Data from the Web. WoD is exploited not only to create these tasks, but also to relate them to physical locations and to a set of associated concepts. Thus, these tasks can be exploited by non-formal ubiquitous learning applications while are still related to formal education. Further, the task generation process is scalable thanks to its use of the WoD. In our example, 32 templates were enough to obtain $16 \mathrm{~K}$ tasks. As the data is gathered from third-party datasets, there is almost no cost for us associated to its maintenance.

In our approach the templates play a key role. Alternative solutions used in the literature are rule-based or statistical methods. Nevertheless, these strategies are only able to create tasks that do not differ much from the surface structure of the input [22]. Instead, the templates used to create the tasks gave us the possibility to offer a wide variety of tasks, including those related to higher-level thinking, thus overcoming a problem detected in the literature [3, 8, 22].

Our task-creation approach implies the creation of a Domain $\mathrm{KB}$ out of data from the Web and a deep analysis of teachers requirements. These are time-consuming activities that require detailed knowledge about the domain and an analysis of teachers requirements (see section section 3 ). Nevertheless, this effort can be partially reused when extend- ing our work. For example, if we integrate in our Domain Knowledge Base a dataset of monuments of another Spanish region, we hope to obtain several thousands of new tasks, located in this other region, by applying the same templates. For this integration of new datasets we should explore automated entity resolution methods, possibly a combination of label comparisons and blocking methods such as [4]. This way, we will avoid the potential scalability problem of our current solution, which includes a manual identity resolution step.

The definition of templates is another time-demanding step in our task creation approach. As part of our future work we will develop an application to support a community of teachers and TEL experts to co-create learning tasks templates. Again, we expect to reduce the time required to create these templates when we apply this approach to other domains or educational levels, because the structure of a contextualized learning task will be very similar (if not the same) for other domains. In our previous work we successfully replicated a strategy to create MCQs for several domains covered in the WoD [35]. However, more research is needed to understand the details of teaching and learning other domains. For example, a similar way to relate formal and informal learning processes may be relevant for domains like Forestry Engineering or Geography, but it may not be the case for Medicine or Physics.

When assessing the tasks, we found out that teachers' perception varies depending on the type of template used to create these tasks. Teachers' perception was very positive in all the cases, but it was difficult to state the difficulty level of the tasks obtained from the List templates [21]. To overcome this problem we can use a similar heuristic as in our previous work [35]. The basis of that heuristic is that those concepts whose Wikipedia pages have less incoming links are less popular, so the tasks (MCQs in [35]) related to them are more difficult. As an example, as the Wikipedia page that describes "Bell-gable" has less incoming links than the one that describes "Nave", this heuristic estimates that a task related to bell-gables is more difficult than other related to naves even if they are obtained from the same template. Another, easier solution, would be to state several manuallycurated lists of elements; thus, we can separate those elements that the learner is only expected to name (e.g., "bellgable" or "ambulatory"), from those that the learner is expected to analyze (e.g., "nave" or "vault").

Our study also illustrates how the datasets available on the WoD influences the tasks created. In our case, we gathered data from a dataset published by the Regional Government, from two datasets that mirror Wikipedia data. While the former is a dataset created by an authority, Wikipedia is created by a community of users. Hence, the tasks obtained are affected by the quality of Wikipedia articles, which are commonly of high quality [13] but are sometimes incorrectly labeled [17]. As a consequence, during the evaluation we found an incorrect task. On the other hand, these three datasets do not provide as much data about historical buildings as we would like: they do not publish information about historical 
events or social aspects related to the monuments; nor they describe civil buildings (e.g., train stations or streets) that could well be analyzed from the historical perspective; nor they contain information about which elements of the building are specially relevant.

These limitations could be partially overcome integrating other open datasets. For example, the Spanish National Library ${ }^{15}$ and the registry of museums in Castile and Leon ${ }^{16}$ offer data that can complement the descriptions of our Domain KB. Another more interesting solution is to enable a community of teachers and TEL experts to enrich and curate the Domain KB by offering them a data annotation application. Thus, this community can describe new buildings, enrich and curate the existing descriptions and provide additional information that is currently missing in the Web of Data (e.g., which elements of a building are of especial importance). This way, we can combine the efficiency and scalability benefits of the automatic creation of learning tasks while giving the control to the community of users to obtain a wider variety of tasks.

We would also like to underline that the exploitation of datasets that contain local and regional information is a value in itself. Indeed, we are in contact with both the Spanish DBpedia and the Castile and Leon data providers, as they asked our feedback after our data consumption experience.

\section{Conclusions and future work}

This paper presents an approach to semi-automatically create a dataset of contextualized learning tasks out of data available in the WoD. This approach consists in retrieving data from the Web to generate a Domain KB and, later on, apply some templates to create the learning tasks. We used this approach for the domain of History of Art in Castile and Leon and we obtained a dataset containing $16 \mathrm{~K}$ contextualized tasks related to $2 \mathrm{~K}$ historical buildings of this Spanish region. An evaluation with teachers shows that they would accept their students to carry out the tasks generated. They also consider the majority of these tasks as relevant, significant and with a reasonable difficulty level.

The approach to create contextualized learning tasks has three differentiating characteristics. First, it further exploits the WoD potential by integrating data from several sources; thus, it manages more and richer descriptions of historical buildings. Second, the learning tasks obtained are contextualized by stating their geolocation and the topics they covered; thus, they can well be used to bridge between formal and non-formal learning processes, which is on the focus of current educational trends, such as smart, ubiquitous, or mobile learning. Third, we also considered learning tasks that promote higher-level thinking, mimicking the tasks that teachers would ask in specific locations.

This is a first step in a long process where we foresee many interesting research challenges. In the short term we

\footnotetext{
$15_{\text {http: //datos.bne.es/inicio.html }}$

16 https://datosabiertos.jcyl.es/web/jcyl/risp/es/cultura-ocio/ museos/1284197401971. json
}

will extend our current proposal to the rest of Spain. As mentioned in section 6 , this will require to explore entity resolution methods not to hinder the scalability of our approach. We also plan to use this same approach to create tasks about other domains and education levels; particularly, Forestry Engineering for higher-education learners. For this purpose we plan to exploit the Spanish National Forestry Inventory ${ }^{17}$ together with the Spanish and English versions of DBpedia. Thus, we will prove whether this approach can actually be easily transferred to other domains and languages.

We will also work to integrate the semi-automatic task generation into real learning processes. Indeed, we already have a first version of Casual Learn, an application that offers the tasks generated to the learners depending on their geolocation [31]. We keep working on Casual Learn to integrate it into a Smart Learning Environment (SLE) [14]. Our key idea is to relate each task to a set of keywords that correspond to Wikipedia concepts (obtained from the DBpedia descriptions out of which the tasks is created); then, the learner will only get recommendations of tasks whose keywords are related to the learning design deployed by the teacher in the SLE [30]. We will also gather data from the use of Casual Learn in real settings. This will enable us to further assess the tasks created and to understand how students perceive them. Indeed, the use of the tasks by the students will also be useful to assess their difficulty level, together with the methods mentioned in section 6.

Finally, as part of this integration into real learning processes, we will propose an annotation application for the community of teachers and TEL experts. As explained in section 6, this annotation application should let its users enrich and curate the data in the Domain Knowledge Base. It should also let them create new templates and obtain learning tasks out of them. But it is still a question how to design such an annotation tool in a way that all the data complexity is abstracted to its users.

\section{Declaration of competing interest}

The authors declared that they had no conflicts of interest with respect to their authorship or the publication of this article.

\section{Acknowledgement}

This research was partially funded by the European Regional Development Fund and the Regional Council of Education of Castile and Leon under grant VA257P18, and the European Regional Development Fund and the National Research Agency of the Spanish Ministry of Science, Innovation and Universities, under project grant TIN2017-85179C3-2-R. The authors also want to thank the high-school teachers who participated in this research.

\footnotetext{
17 https://www.miteco.gob.es/es/biodiversidad/servicios/ banco-datos-naturaleza/informacion-disponible/ifn3_bbdd_descargas. htm. aspx
} 
Supporting contextualized learning with LOD

\begin{tabular}{ll}
\hline Prefix & URI \\
\hline \hline rdfs: & http://www.w3.org/2000/01/rdf-schema\# \\
foaf: & http://xmlns.com/foaf/0.1/ \\
owl: & http://www.w3.org/2002/07/owl\# \\
dcterms: & http://purl.org/dc/terms/ \\
db: & http://es.dbpedia.org/resource/ \\
dbp: & http://dbpedia.org/property/ \\
dbo: & http://dbpedia.org/ontology/ \\
dbcat: & http://es.dbpedia.org/resource/Categoría: \\
dbf: & http://commons.wikimedia.org/wiki/Special:FilePath/ \\
ns: & a personal valid namespace \\
\hline
\end{tabular}

Table 9

Prefixes used in the present work and their corresponding expanded URI.

\section{A. Prefixes and Namespaces}

Table 9 lists the prefixes used in the present work and their corresponding extended URI.

\section{References}

[1] Al-Yahya, M., 2014. Ontology-based multiple choice question generation. Recent Advances in Information Technology doi:10.1155/2014/ 274949.

[2] Alsubai, T., Parsia, B., Sattler, U., 2014. Generating multiple choice questions from ontologies: Lessons learnt, in: Proceedings of the 11th International Workshop on OWL: Experiences and Directions, CEUR, Riva del Garda (Italy). pp. 73-84.

[3] Alsubait, T., Parsia, B., Sattler, U., 2016. Ontology-based multiple choice question generation. Künstliche Intelligenz 30, 183-188.

[4] de Assis-Costa, G., Parente-de Oliviera, J., 2016. A Blocking Scheme for Entity Resolution in the Semantic Web, in: Proceedings of the 30th IEEE International Conference on Advances Information Networking and Applications, IEEE, Crans-Montana (Switzerland). pp. 1138-1145.

[5] Berners-Lee, T., 2006. Linked Data - Design Issues. URL: http://www.w3.org/DesignIssues/LinkedData.html, last visit October 2020.

[6] Bloom, B., 1956. Taxonomy of Educational Objectives (Handbook 1: Cognitive Domain). New York: David McKay Co., Inc.

[7] Bratsas, C., Chrysou, D.E., Eftychiadou, E., Kontokostas, D., Bamidis, P.D., Antoniou, I., 2012. Semantic Web Game Based Learning: An I18n approach with Greek DBpedia, in: Proceedings of the 2nd International Workshop on Learning and Education with the Web of Data (LiLe-2012 at WWW-2012), CEUR, Lyon, France. pp. 1-6.

[8] Demaidi, M., Gaber, M., Filer, N., 2017. Evaluating the quality of the ontology-based auto-generated questions. Smart Learning Environments 4, 7. doi:https: //doi .org/10.1186/s40561-017-0046-6.

[9] FitzGerald, E., 2012. Creating user-generated content for locationbased learning: an authoring framework. Journal of Computer Assisted Learning 3, 195-207.

[10] Fogus, M., Vinoski, S., 2013. Functional JavaScript: Introducing Functional Programming with Underscore.js. O'Reilly, Cambridge (UK).

[11] Foulonneau, M., 2011. Generating educational assessment items from linked open data: the case of DBpedia, in: Proceedings of the 8th Extended Semantic Web Conference, Springer, Heraklion, Greece. pp. 16-27.

[12] Foulonneau, M., Ras, E., 2013. Using educational domain models for automatic item generation beyond factual knowledge assessment, in: Proceedings of the 8th European Conference on Technology Enhanced Learning, Springer, Paphos, Cyprus. pp. 442-447.

[13] Giles, J., 2005. Internet encyclopaedias go head to head. Nature 438, 900-901.
[14] Gros, B., 2016. The design of smart educational environments. Smart Learning Environments 3, 1-11.

[15] Gwet, K.L., 2008. Computing inter-rater reliability and its variance in the presence of high agreement. British Journal of Mathematical and Statistical Psychology 61, 29-48.

[16] Heath, T., Bizer, C., 2011. Linked Data: Evolving the Web into a global data space. Synthesis Lectures on the Semantic Web: Theory and Technology. first ed., Morgan \& Claypool. URL: http: //linkeddatabook. com/editions/1.0/, last visit October 2020.

[17] Hu, M., Lim, E., Sun, A., Lauw, H., Vuong, B., 2007. Measuring article quality in Wikipedia: Models and evaluation, in: Proceedings of the 16th ACM Conference on Information and Knowledge Management, ACM, Lisbon (Portugal). pp. 243-252.

[18] Hwang, G.J., Tsai, C.C., Yang, S.J., 2008. Criteria, strategies and research issues of context-aware ubiquitous learning. Journal of Educational Technology Society 11, 81-91.

[19] Juan, J.M., Bingham, R.S., Gryna, F.M., 1988. The Quality Control Handbook, 4th Edition. McGraw-Hill Inc., Cambridge (UK).

[20] Kelle-Pereira, C., Matsui-Siqueira, S.W., Pereira-Nunes, B., Dietze, S., 2017. Linked Data in education: A survey and a synthesis of actual research and future challenges. IEEE Transactions on Learning Technologies 11, 400-412.

[21] Kurdi, G., Leo, J., Matentzoglu, N., Parsia, B., Sattler, U., Forge, S., Donato, G., Dowling, W., 2020a. A comparative study of methods for a priori prediction of MCQ difficulty. Semantic Web Journal. In press.

[22] Kurdi, G., Leo, J., Parsia, B., Sattler, U., Al-Emari, S., 2020b. A systematic review of automatic question generation for educational purposes. International Journal of Artificial Intelligence in Education 30, 121-204

[23] Landis, J.R., Koch, G.G., 1977. The measurement of observer agreement for categorical data. Biometrics 33, 159-174.

[24] Leo, J., Kurdi, G., Matentzoglu, N., Parsia, B., Sattler, U., Forge, S., G., D., Dowling, W., 2019. Ontology-based generation of medical, multi-term MCQs. International Journal of Artificial Intelligence in Education 29, 145-188.

[25] Marsick, V.J., Watkins, K.E., 2001. Informal and incidental learning. New directions for adult and continuing education 2001, 25-34.

[26] Mynarz, J., Zeman, V., 2016. DB-quiz: a DBpedia-backed knowledge game, in: Proceedings of the 12th International Conference on Semantic Systems, Leipzig, Germany. pp. 121-124.

[27] Peters, I., Stock, W., 2007. Folksonomy and information retrieval, in: Proceedings of the American Society for Information Science and Technology 44, Milwaukee, Wisconsin (USA). pp. 1-28.

[28] Pishtari, G., Rodríguez-Triana, M., Sarmiento-Márquez, E., PérezSanagustí, M., Ruiz-Calleja, A., Santos, P., Prieto, L., SerranoIglesias, S., Väljataga, T., 2020. Learning design and learning analytics in mobile and ubiquitous learning: A systematic review. British Journal of Educational Technology. 4, 1078-1100.

[29] Prieto-Pariente, J., 2016. La gestión de las actividades de enseñanza aprendizaje bajo el modelo curricular de las competencias básicas en 
el área de tecnología. Ph.D. thesis. University of Valladolid.

[30] Ruiz-Calleja, A., Asensio-Pérez, J., Vega-Gorgojo, G., MartínezMonés, A., Bote-Lorenzo, M., Dimitriadis, Y., Gómez-Sánchez, E., Serrano-Iglesias, S., 2020a. An ontology to connect formal and informal learning in smart learning environments, in: Proceedings of the XXII International Symposium on Computers in Education, CEUR, Málaga, Spain. In press.

[31] Ruiz-Calleja, A., Bote-Lorenzo, M., Vega-Gorgojo, G., SerranoIglesias, S., García-Zarza, P., Asensio-Pérez, J., Gómez-Sánchez, E., 2020b. Casual Learn: A smart application to learn History of Art, in: Proceedings of the European Conference on Technology Enhanced Learning (ECTEL), Springer, Heidelberg, Germany. pp. 472-476.

[32] Šimko, M., Barla, M., Bieliková, M., 2010. ALEF: A framework for adaptive web-based learning 2.0, in: Proceedings of the IFIP International Conference on Key Competencies in the Knowledge Society, Springer, Brisbane, Australia. pp. 367-378.

[33] Tarasowa, D., Khalili, A., Auer, S., 2015. Crowdlearn: Crowdsourcing the creation of highly-structured e-learning content. International Journal of Engineering Pedagogy 5, 47-54.

[34] Traxler, J., 2009. Learning in a mobile age. International Journal of Mobile and Blended Learning 1, 1-12.

[35] Vega-Gorgojo, G., 2019. Clover quiz: A trivia game powered by DBpedia. Semantic Web Journal 10, 779-793.

[36] Vega-Gorgojo, G., Asensio-Pérez, J., Gómez-Sánchez, E., BoteLorenzo, M., Muñoz-Cristóbal, J., Ruiz-Calleja, A., 2015. A review of Linked Data proposals in the learning domain. Journal of Universal Computer Science 21, 326-364.

[37] Väljataga, T., Mettis, K., 2016. Turning zoos into smart learning ecosystems. Interaction Design and Architecture(s) Journal 39, 114133.

[38] Ying, M., Yang, H., 2008. Computer-aided generation of item banks based on ontology and Bloom's taxonomy, in: Proceedings of the 7th International Conference on Advances in Web Based Learning, Springer, Jinhua, China. pp. 157-166.

[39] Yu, S., Yang, X., Cheng, G., Wang, M., 2014. From learning object to learning cell: A resource organization model for ubiquitous learning. Educational Technology \& Society 2, 206-224.

[40] Zavala, L., Mendoza, B., 2018. On the use of semantic-based aig to automatically generate programming exercises, in: Proceedings of the 49th ACM Technical Symposium on Computer Science Education, ACM, Baltimore, Maryland, USA. pp. 14-19.

[41] Zaveri, A., Rula, A., Maurino, A., Pietrobon, R., Lehmann, J., Auer, S., 2016. Quality assessment for linked data: A survey. The Semantic Web Journal 1, 63-93.

[42] Zitko, B., Stankov, S., Rosic, M., Grubisic, A., 2009. Dynamic test generation over ontology-based knowledge representation in authoring shell. Expert Systems with Applications 36, 8185-8196. 